\title{
Disclination ensembles in graphene
}

\author{
M.A. Rozhkov ${ }^{1}$, A.L. Kolesnikova ${ }^{1,2}$, I.S. Yasnikov ${ }^{3}$, and A.E. Romanov ${ }^{1}$ \\ ${ }^{1}$ ITMO University, 49 Kronverkskiy Pr., St. Petersburg 197101, Russia \\ E-mail: alexey.romanov@niuitmo.ru \\ ${ }^{2}$ Institute of Problems of Mechanical Engineering RAS, 61 Bolshoj Pr., Vas. Ostrov, St. Petersburg 199178, Russia \\ ${ }^{3}$ Togliatti State University, 14 Belorusskaya Str., Togliatti, 445020, Russia
}

Received 10 April, 2018, published online July 26, 2018

\begin{abstract}
We consider graphene disclination networks (DNs) - periodic distributions of disclination defects. Disclinations manifest themselves as 4-, 5-, 7- or 8-member carbon rings in otherwise 6-member ring ideal 2D graphene crystal lattice. Limiting cases of graphene-like 2D carbon lattices without 6-member motives, i.e., pseudographenes, are also studied. The geometry and energy of disclinated 2D carbon configurations are analyzed with the help of molecular dynamics (MD) simulation technique. A comparison of the obtained MD results with analytical calculations within the framework of the theory of defects of elastic continuum is presented.
\end{abstract}

Keywords: graphene; pseudo-graphene; disclination; disclinated carbon ring; disclination quadrupole; disclination network; molecular dynamics.

\section{Introduction}

With the discovery and mass fabrication of graphene $[1,2]$ and with a large number of experimental studies of graphene structure, see for example [3-18], the theoretical interest to 2D atomic crystals has grown considerably. Along with the analysis of the properties of ideal graphene lattice containing only 6-member carbon rings (hexagons) it was found that various defects exist in graphene and graphene-like carbon lattices, i.e. rings in the form of square, pentagon, heptagon, or octagon [19-21]. Big efforts were then spent to the understanding the behavior of graphene with defect walls and chains, i.e., polycrystalline graphenes with grain and intercrystallite boundaries [18-34]. In particular, the effect of the localized defects on the physical and mechanical properties of graphene was analyzed. The studies of defects distributed throughout the graphene sheet have so far been less developed [35-37]. In the limiting case of a dense packing of pentagons with octagons or heptagons in graphene, two 2D carbon modifications (pseudo-graphenes) were described: pentagon-octagon (PO) graphene [35] and phagraphene [37].

The main technique to model graphene and other 2D crystals with defects and without them is molecular dynamics (MD) simulation, e.g. see Refs. 28, 33, 34. Within $\mathrm{MD}$ approach, the information about equilibrium atomic configurations and the energy of these configurations can be delivered. The other known approach to investigate defects in 2D crystals operates with the analytical methods of the theory of defects in solids [38-43].

Important feature of defects, which are possible in graphene lattice, is their intrinsic connection to disclinations - defects of rotational type [44,45]. Using disclination nomenclature, 4-, 5- or 7-, 8-member rings are viewed as disclinated rings and are classified as the cores of positive or negative wedge disclinations, respectively [45].

In the present work, we report on the results of modeling graphene and graphene-like carbon structures with distributed disclinated rings utilizing both methods of MD simulation and theory of elasticity for 2D solid structures.

\section{Background}

Low-dimensional systems in the condensed matter physics have always provoked genuine interest among researchers. Wherein an analysis of their defective structure is a hot topic in scientific periodicals. For example in Refs. 38, 41, 42 Natsik and Smirnov presented the theoretical study of the properties of intrinsic dislocation- and crowdion-type structural defects in 2D crystals. The results obtained by using the continual theory were improved by comparing with the results of numerical analysis by the methods of MD simulation 
of atomic structure of dislocations and crowdions in a hexagonal lattice 2D crystals.

In addition to concept of dislocations, pioneering ideas on the disclinations in 2D crystals have been outlined four decades ago by Harris [46]. In this sense, the use of the disclination concept in two-dimensional hexagonal graphene lattice seems reasonable. Typical defects in 2D hexagonal graphene lattice - square, pentagonal, heptagonal, octagonal carbon rings- and their ensembles such as internal boundaries and two-dimensional distributions were successfully described by wedge disclinations [19,33,34]. In addition, disclinations can move 2D flat crystal into the third dimension, thereby lowering the energy of elastic distortions, as it occurs in fullerene macromolecules [47].
In the theory of defects in 3D solids, two types of linear defects, namely, dislocations as carriers of translational deformation modes and disclinations that are responsible for rotational deformation modes, are distinguished [44]. Despite the fact that the concept of disclinations was introduced by Vito Volterra into mechanics in solids in 1907, the approach based on the analysis of rotational deformation modes in real crystals actually revealed itself only at the end of the last century [45]. It should be noted that the disclination approach is effective for describing the properties of $3 \mathrm{D}$ crystals in the form of small particles and microcrystals with pentagonal symmetry $[48,49]$.
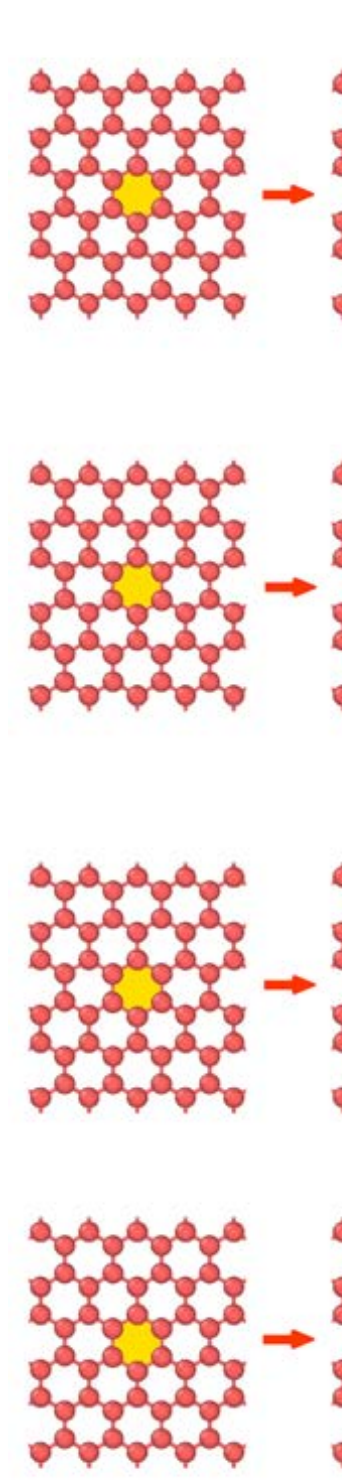

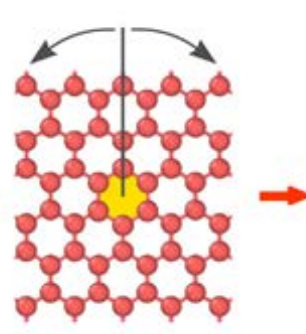

(a)
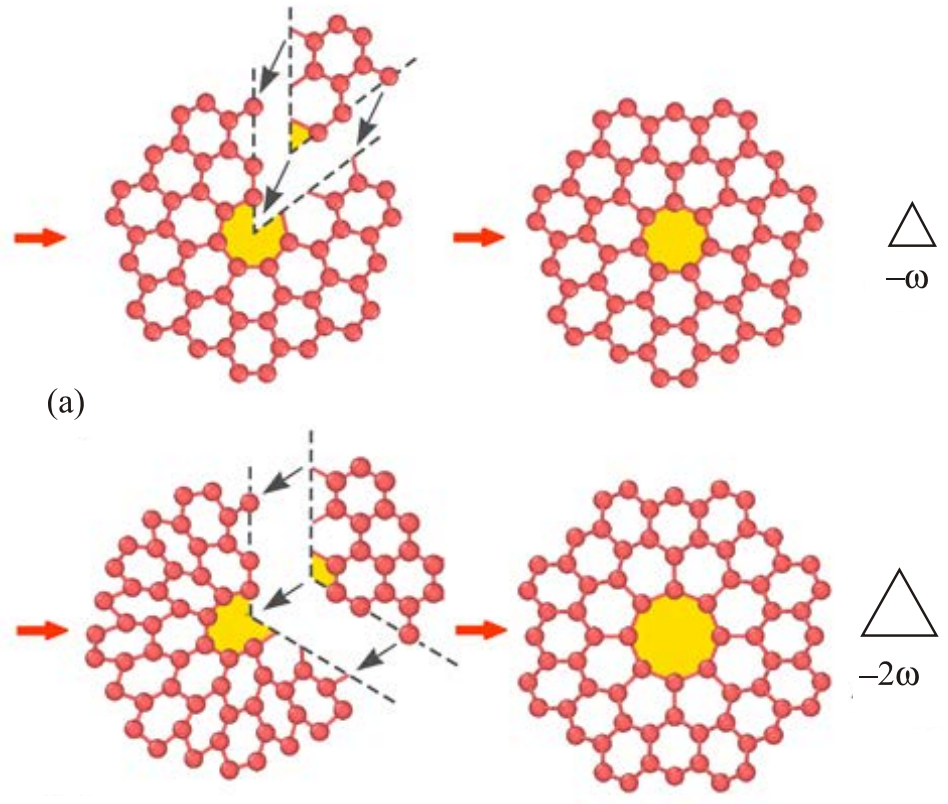

(b)
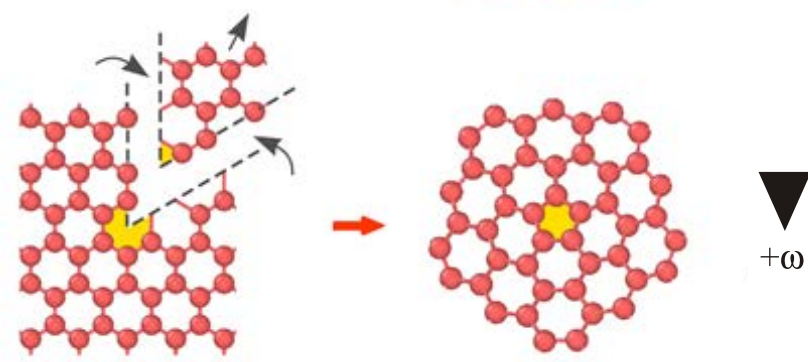

(c)
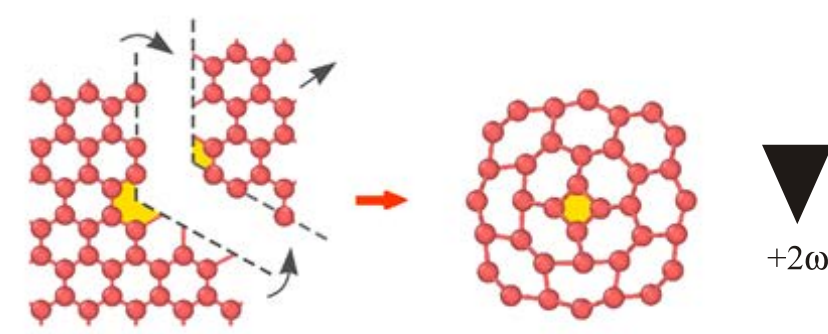

(d)

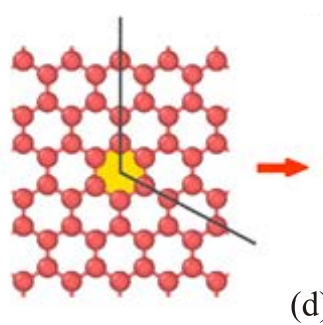

Fig. 1. (Color online) Volterra's procedure for the formation of wedge disclinations in 2D hexagonal crystal lattice: (a) negative disclination and associated 7-member ring; (b) negative disclination and associated 8-member ring; (c) positive disclination and associated 5-member ring; (d) positive disclination and associated 4-member ring. Minimal magnitude of disclination strength in hexagonal lattice is $\omega=\pi / 3$. Negative and positive disclinations are denoted by empty and black triangles, respectively (adopted from [34]). 
Volterra's procedure for the formation of wedge disclinations in 2D hexagonal crystal lattice is presented in Fig. 1. Wedge disclinations are formed by inserting or removing a wedge of 60 or 120 degrees from a hexagonal lattice [34,44-46], leaving in the vertex of this wedge, 7-, 5-, 8- or 4-member carbon rings, in another words, disclinated rings. The strength (or charge) of the wedge disclination $\omega$ is determinate by the magnitude of the wedge angle: $\omega=-\pi / 3,+\pi / 3,-2 \pi / 3,+2 \pi / 3$.

It is known, that single disclination introduces global distortion in the crystal lattice, see for example Refs. 44, 45, and, according to the continual theory of disclinations, its energy for plane elasticity depends quadratically on the characteristic size of the crystal [44]. In particular, energy $E$ of the wedge disclination in the center of elastically isotropic disk obeys formula [44]:

$$
E=\frac{1}{8} D \omega^{2} R_{0}^{2}
$$

where $\omega$ is the strength of the disclination, $R_{0}$ is the radius of the disk, $D=G(1+v) / 2 \pi$ for a $2 D$ disk $[38,40,44], G$ is the shear modulus in units Force/Length, and $v$ is Poisson ratio.

Disclinations in solids are realized in the form of selfscreening ensembles, i.e., dipoles and quadrupoles [44,45]. In graphene, self-screening ensembles of disclinations can be present in the form of grain boundaries and intercrystallite boundaries, i.e. in the form of linear defects, see in details in Refs. 18, 27, 33, 34, 40.

\section{Numerical and analytical methods used}

In this paper, we utilize the method of molecular dynamics (MD) simulation as a numerical approach, the results of which are also used as an input for analytical modelling in the framework of the disclination theory. We would like to answer the question whether we can estimate the energy of disclination configurations in graphene using formulas for the energies of screened disclinational config-

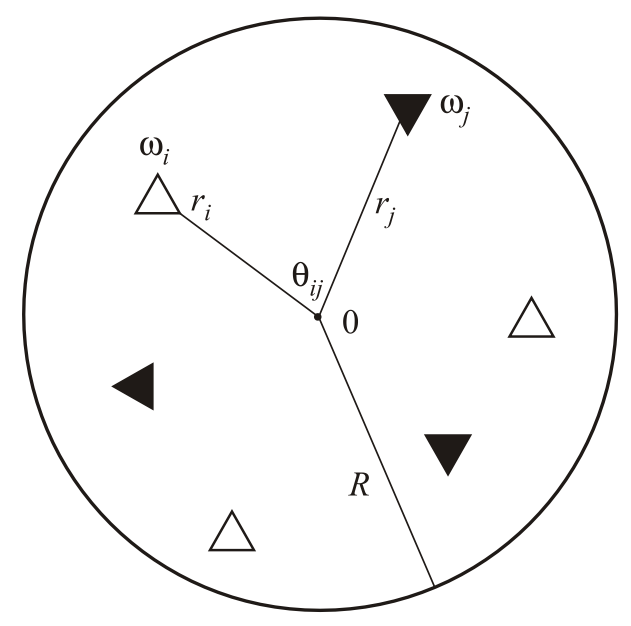

Fig. 2. Schematics for calculating energy of the disclination ensemble in an elastic disk.

urations without any additional MD simulation. In this sense, the sharing and comparison of the results of two independent methods such as theoretical and numerical approaches give an algorithm for choosing a method for solving a particular class of problems when describing graphene-like configurations.

MD simulations of ideal graphene and graphene with disclinated carbon rings were performed with LAMMPS software package [50]. The interatomic interactions were described by the adaptive AIREBO potential [51]. The post-processing and images of equilibrium atomic structures were produced with software package OVITO [52]. The MD simulation was performed at zero temperature, and Polak-Ribiere version of the conjugate gradient algorithm for energy minimization was used [53].

To find the energies of disclination ensembles in graphene in the framework of the analytical approach one can use the results of Ref. 54 for energy $E_{N}$ of $N$ disclinations in an elastic disk. In Fig. 2 the geometrical scheme for calculation of energy $E_{N}$ is shown. In such a geometry $E_{N}$ is expressed by the following formula:

$$
\begin{gathered}
E_{N}=\frac{G(1+v)}{8 \pi}\left(\sum_{i}^{N} \frac{\omega_{i}^{2} R^{2}}{2}\left(1-\frac{r_{i}}{R}\right)+\right. \\
\left.+\sum_{i=1}^{N} \sum_{j=i+1}^{N} \omega_{i} \omega_{j}\left[\left(r_{i}^{2}+r_{j}^{2}-2 r_{j} r_{j} \cos \theta_{i j}\right) \ln \frac{R^{2}\left(r_{i}^{2}+r_{j}^{2}-2 r_{i} r_{j} \cos \theta_{i j}\right)}{r_{i}^{2} r_{j}^{2}-2 R^{2} r_{i} r_{j} \cos \theta_{i j}+R^{4}}+R^{2}-r_{i}^{2}-r_{j}^{2}+\frac{r_{i}^{2} r_{j}^{2}}{R^{2}}\right]\right),
\end{gathered}
$$

where $\omega_{i}$ is a strength of the $i$-disclination; $r_{i}$ is a distance between center of disk and $i$-disclination; $\theta_{i j}$ is an angle between radiuses of $i$ - and $j$ - disclinations; $R$ is a radius of the disc. In Eq. (2) we take into account that the disk is infinitely thin, i.e., is a $2 \mathrm{D}$ solid.

\section{Results and discussion}

The essence of our MD simulation is as follows. In Fig. 3, MD modelled graphene-like sheets with the most dense networks of disclinations are presented. These 2D crystals cannot be called "graphene", because they have 
either very few 6-member atomic rings characteristic for hexagonal graphene lattice (Fig. 3(a)), or do not have them at all (Figs. 3(b)-(d)). They can be better classified as graphene-like carbon structures or pseudo-graphenes.

One of the crystals composed with 5- and 7-member carbon rings (Figs. 3(a),(b)) is phagraphene [37] (Fig. 3(a)), in which 6-member rings, usual for graphene, are required for joining disclinated rings. The disclination strengths $\omega$ in phagraphene and crystal " $5-7$ B" (Fig. 2(a),(b)) are $+\pi / 3$ and $-\pi / 3$. Pseudo-graphene, composed with 5- and 8-member carbon rings (Fig. 2(b)), is pentagon-octagon (PO) graphene [35], where $\omega=+\pi / 3$ and $-2 \pi / 3$. Pseudo-graphene, composed with 4- and 8-member carbon rings is presented in Fig. 3(c). In this case, $\omega=+2 \pi / 3$ and $-2 \pi / 3$. In our classification, previously adopted for structural units in graphene and linear defects composed of them [33,34], these crystals have the designations "5-7 A", "5-7 B", "5-8-5 D" and "4-8" (Fig. 3).

The pseudo-graphenes, considered here, can be constructed using the linear defects of 2D hexagonal lattice. For example, phagraphene can be constructed from the favorite symmetric grain boundaries "docked" to each other $[27,40]$ and PO graphene can be composed from linear defects first described in Ref. 18 and then also modelled in Ref. 34, and pseudo-graphene "4-8" can be composed from linear defects " $4-8$ ", introduced and described in Ref. 34.

In Fig. 4, the differences between the average energies per atom for the pseudo-graphenes $\bar{e}_{a}$ and the ideal graphene $\bar{e}_{a}^{0}$ are presented: $\Delta \bar{e}_{a}=\bar{e}_{a}-\bar{e}_{a}^{0}$. In diagram, zero energy is the energy per atom for the ideal graphene $\bar{e}_{a}^{0}$. On the one hand, when $\bar{\rho}_{a}$ and $\bar{\rho}_{a}^{0}$ are the atomic densities of pseudo-graphene and the ideal graphene, correspondingly, the energy $\Delta \bar{e}=\bar{e}_{a} \bar{\rho}_{a}-\bar{e}_{a}^{0} \bar{\rho}_{a}^{0}$ is the difference

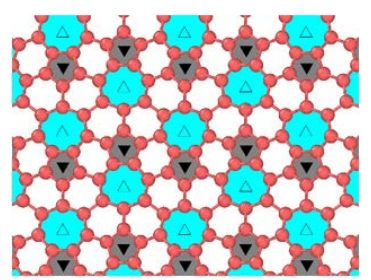

5-7 A (phagraphene [37])

(a)

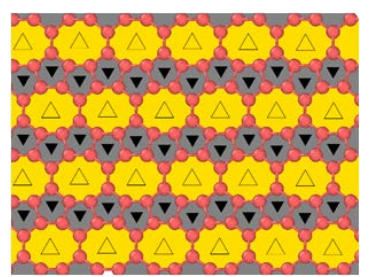

5-8-5 D (PO graphene [35])

(c)

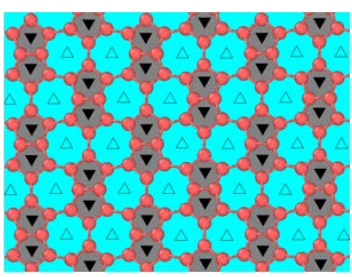

5-7 B

(b)

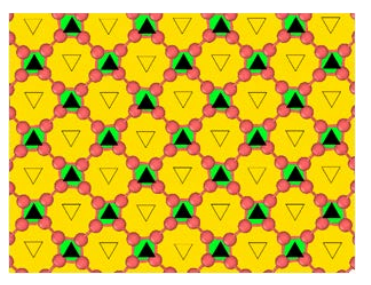

4-8

(d)
Fig. 3. (Color online) Pseudo-graphene crystals with disclination networks (DNs). Red circles denote carbon atoms. Empty and black triangles denote negative and positive disclinations, respectively.

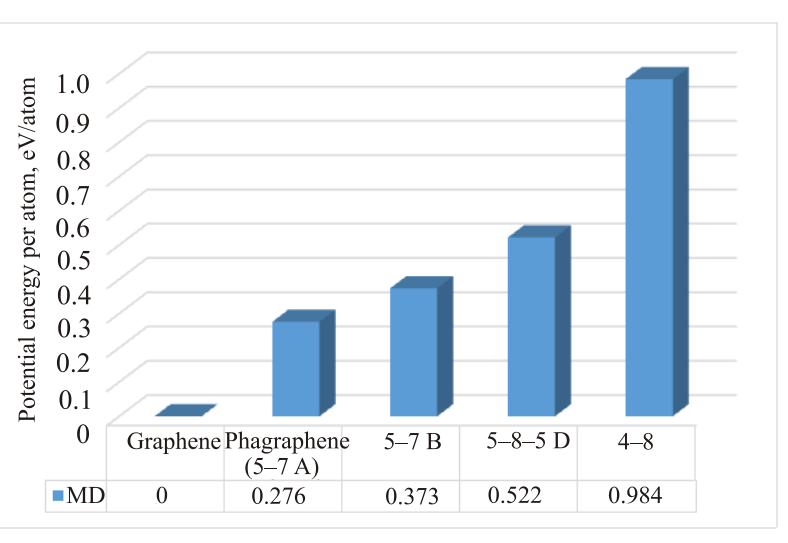

Fig. 4. Energy of the modeled pseudo-graphenes.

in the energies of the pseudo-graphene and graphene per unit area of the crystal. Therefore $\Delta \bar{e}$ can be treated as the average energy per unit area of the disclination network (DN) $e_{D N}$ embedded into the graphene crystal (Fig. 3).

The energy $e_{D N}$ can be also found with the analytical formulas of disclination theory, i.e., Eq. (2), for each of studied pseudo-graphenes. To do this, the self-screened DN should be chosen. If ensemble of $N$ disclinations satisfies the following conditions: zero disclination charge and zero disclination dipole moment, then it is selfscreened configuration, and its energy does not depend on the external screening parameter $R$. The simplest selfscreening disclination ensembles are quadrupoles in the forms of a rectangle or line, and their energies are known,

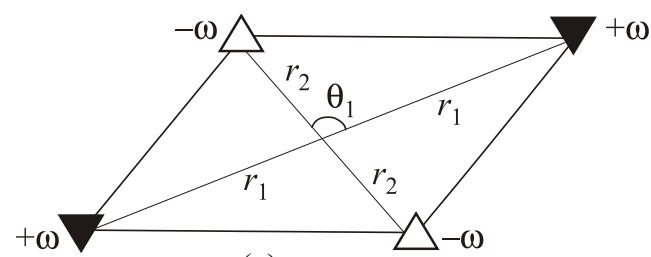

(a)

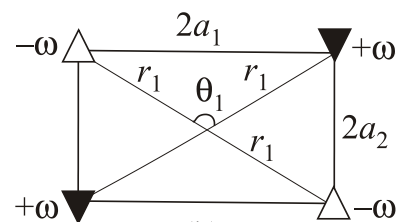

(b)

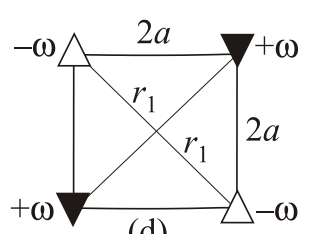

(d)

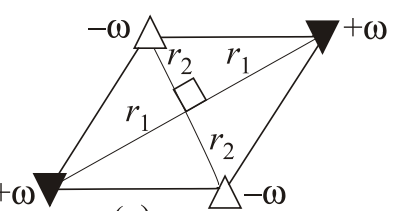

(c)

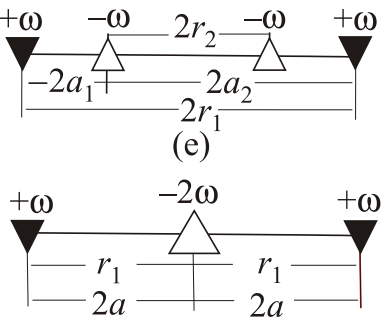

(f)
Fig. 5. Self-screened disclination quadrupoles. Parallelogram (a), special cases of parallelogram: a rectangle (b), a rhombus (c), a quadrate (d), and line quadrupoles (e), (f) as degenerate parallelograms. 
e.g., see Refs. 44, 45. Additional analysis of Eq. (2) shows that the most general self-screening ensembles, i.e., those with the energies that do not depend on the external parameter $R$, are quadrupoles in the form of parallelograms and their particular cases (Fig. 5). These quadrupoles can be recognized in graphene structures as repetitive self-screening ensembles, and hence their energies should be used to calculate the energy of disclination networks $E_{D N}$ as a whole.

The energies of quadrupoles, shown in Fig. 5, have the following algebraic representations:

(a) for the parallelogram (Fig. 5(a))

$$
\begin{gathered}
E_{\mathrm{par}}=\frac{G(1+v) \omega^{2}}{4 \pi}\left(r_{1}^{2} \ln \frac{16 r_{1}^{4}}{\left(r_{1}^{2}+r_{2}^{2}-2 r_{1} r_{2} \cos \theta_{1}\right)\left(r_{1}^{2}+r_{2}^{2}+2 r_{1} r_{2} \cos \theta_{1}\right)}+\right. \\
\left.+r_{2}^{2} \ln \frac{16 r_{2}^{4}}{\left(r_{1}^{2}+r_{2}^{2}-2 r_{1} r_{2} \cos \theta_{1}\right)\left(r_{1}^{2}+r_{2}^{2}+2 r_{1} r_{2} \cos \theta_{1}\right)}+2 r_{1} r_{2} \cos \theta_{1} \ln \frac{r_{1}^{2}+r_{2}^{2}-2 r_{1} r_{2} \cos \theta_{1}}{r_{1}^{2}+r_{2}^{2}+2 r_{1} r_{2} \cos \theta_{1}}\right) ;
\end{gathered}
$$

(b) for the rectangle (Fig. 5(b))

$$
\begin{gathered}
E_{\text {rec }}=\frac{G(1+v) \omega^{2} r_{1}^{2}}{2 \pi}\left(\ln 4-\left(1-\cos \theta_{1}\right) \ln \left(1-\cos \theta_{1}\right)-\left(1+\cos \theta_{1}\right) \ln \left(1+\cos \theta_{1}\right)\right)= \\
=\frac{G(1+v) \omega^{2}}{\pi}\left(a_{1}^{2} \ln \frac{a_{1}^{2}+a_{2}^{2}}{a_{1}^{2}}+a_{2}^{2} \ln \frac{a_{1}^{2}+a_{2}^{2}}{a_{2}^{2}}\right) ;
\end{gathered}
$$

(c) for the rhombus (Fig. 5(c))

$$
E_{\text {rhomb }}=\frac{G(1+v) \omega^{2}}{2 \pi}\left(r_{1}^{2} \ln \frac{4 r_{1}^{2}}{\left(r_{1}^{2}+r_{2}^{2}\right)}+r_{2}^{2} \ln \frac{4 r_{2}^{2}}{\left(r_{1}^{2}+r_{2}^{2}\right)}\right)
$$

(d) for the square (Fig. 5(d))

$$
E_{\text {qudr }}=\frac{G(1+v) \omega^{2} r_{1}^{2}}{\pi} \ln 2=\frac{2 G(1+v) \omega^{2} a^{2}}{\pi} \ln 2 ;
$$

(e) for the line quadrupole (Fig. 5(e))

$$
\begin{gathered}
E_{l q}=\frac{G(1+v) \omega^{2}}{2 \pi}\left(r_{1}^{2} \ln \frac{4 r_{1}^{2}}{\left(r_{1}^{2}-r_{2}^{2}\right)}+r_{2}^{2} \ln \frac{4 r_{2}^{2}}{\left(r_{1}^{2}-r_{2}^{2}\right)}-2 r_{1} r_{2} \ln \frac{\left(r_{1}+r_{2}\right)}{\left(r_{1}-r_{2}\right)}\right)= \\
=\frac{G(1+v) \omega^{2}}{\pi}\left(a_{1}^{2} \ln \frac{a_{2}^{2}-a_{1}^{2}}{a_{1}^{2}}+a_{2}^{2} \ln \frac{a_{2}^{2}-a_{1}^{2}}{a_{2}^{2}}+2 a_{1} a_{2} \ln \frac{a_{2}+a_{1}}{a_{2}-a_{1}}\right), \quad r_{1}>r_{2}, \quad a_{2}>a_{1} ;
\end{gathered}
$$

(f) for the line quadrupole (Fig. 5(f))

$$
E_{l q}=\frac{G(1+v) \omega^{2} r_{1}^{2}}{\pi} \ln 2=\frac{4 G(1+v) \omega^{2} a^{2}}{\pi} \ln 2 .
$$

Formulas (3(b), (d)-(f) were originally given in Ref. 44.

For each crystal with a periodic DN, a suitable disclination quadrupole can be determined for calculating DN energy per unit area $e_{D N}$. For example, for phagraphene (Fig. 3(a)) this is the disclination quadrupole in the form of the parallelogram (Fig. 5(a)), for structure "5-7 B" (Fig. 3(b)) this is the rhombus (Fig. 5(c)), for structure "5-8-5 D" (Fig. 3(c)) this is the line quadrupole
(Fig. 5(f)), and for structure "4-8" (Fig. 3(d)) this is the square (Fig. 5(d)).

In Fig. 6, the square DNs originated from Fig. 3(d) are presented for various motive periods. In Fig. 7, the average energies per atom for graphene with periodic alternating DNs, see Figs. 6(a)-(e), are shown. Crystal marked "4-8 g0" is a pseudo-graphene " $4-8$ ". It follows from the diagram that, with the exception of the tightly packed structure " $4-8 \mathrm{g0}$ ”, 


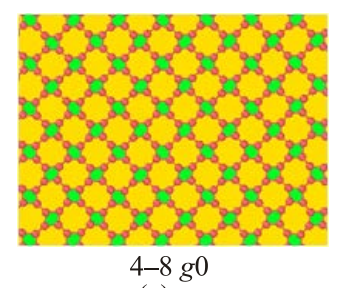

(a)

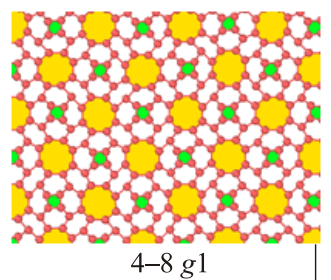

(b)

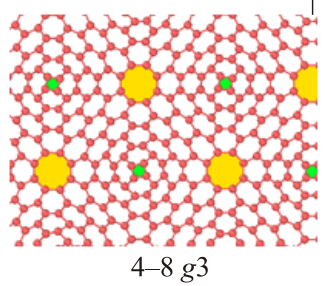

(d)

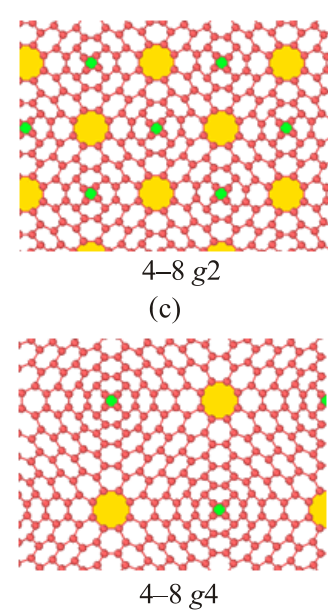

(e)

Fig. 6. (Color online) Networks of 4-member and 8-member carbon rings in graphene as a periodic structures of disclinations of stregth $\omega=+2 \pi / 3$ and $-2 \pi / 3$.

the average energy per atom in the crystal depends weakly on the period of the $\mathrm{DN}$.

In Fig. 8, the average energy per unit area for structures in Fig. 6, as a function of the square of the DN period is shown. The energies are normalized to the energy of a tightly packed structure "4-8 $g 0$ ". The dependences are found from MD simulations (Fig. 8(a), blue dots), calculated with Eq. (3d) (Fig. 8(a), red line), and calculated with Eq. (2) adopted to 4 quadrupoles (Fig. 8(b), grey line). In disclination scheme (Fig. 8(b)), the area related to the quadrupole when calculating the DN energy is highlighted.

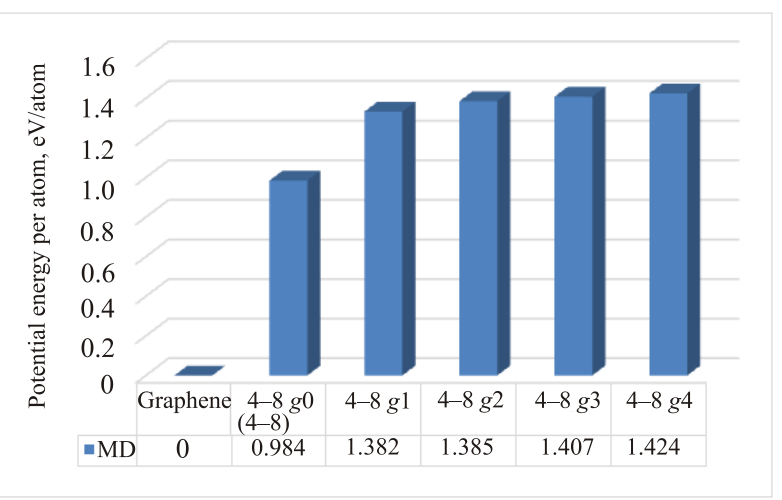

Fig. 7. Energy per carbon atom for graphenes with periodic structures of alternating disclinations, given in Fig. 6. Crystal marked “4-8 $g 0$ ” is a pseudo-graphene “4-8”.
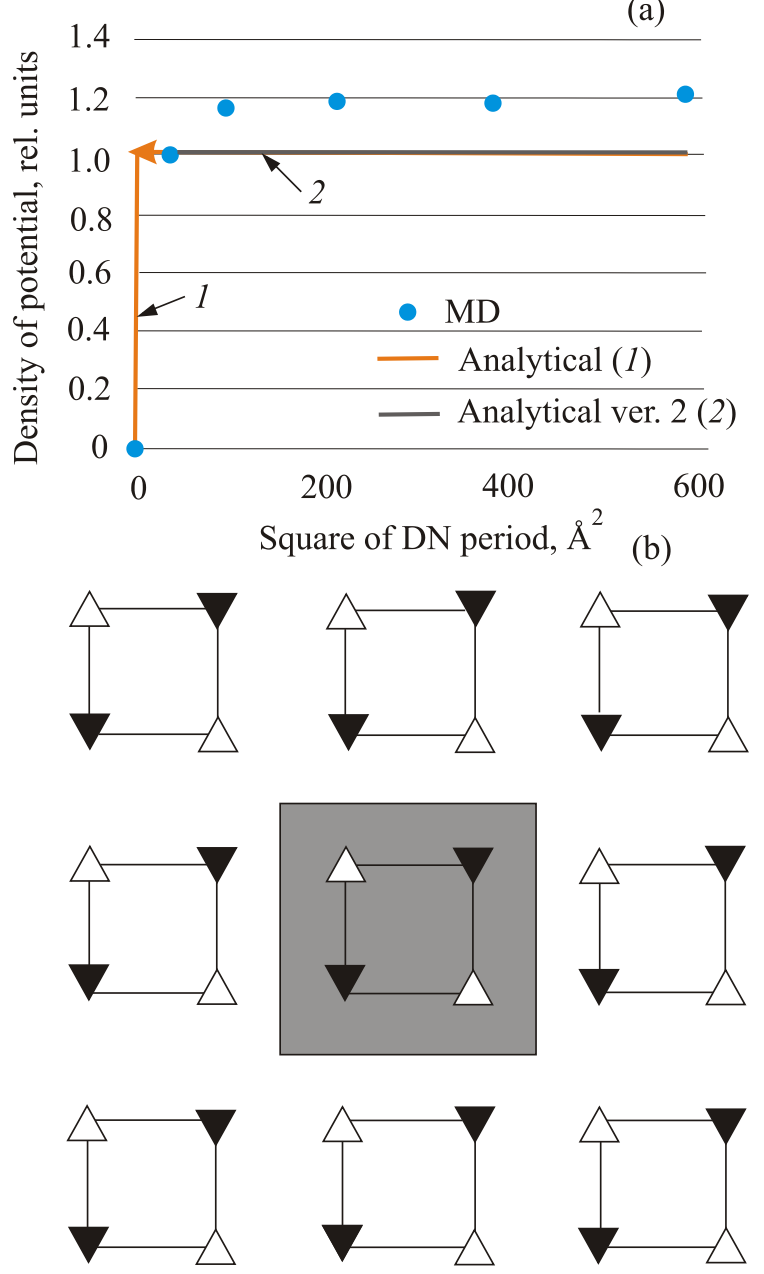

Fig. 8. (Color online) Energy per unit area for structures "4-8", as a function of the square of the disclination network (DN) period. The blue dots correspond to the energies calculated with the help of MD simulation; red (1) and grey (2) lines correspond to the dependences, calculated analytically taking into account 1 and 4 disclination quadrupoles, correspondingly. The energies are normalized to the energy of a tightly packed structure "4-8 g0" shown in Fig. 5(a). In disclination scheme (b), the area related to the quadrupole used in analytical calculation of DN energy, is highlighted.

Along with the investigation of the quadratic DNs shown in Fig. 6, we studied networks containing quadrupoles of disclinations with charges $\omega=+2 \pi / 3$ and $-2 \pi / 3$, which size is the smallest possible in a graphene crystal. In Fig. 7, the single disclination quadrupole in the graphene crystal and its possible formation scheme are given. It can be seen that such a single quadrupole has the shape of a rhombus, because the sizes of the 4-member and 8-member rings, which are the nuclei of disclinations with $\omega=+2 \pi / 3$ and $-2 \pi / 3$, respectively, are significantly different. The elastic distortions induced by the quadrupole in the graphene lattice decay rapidly over a distance of the order of the average size of the quadrupole (Fig. 9(b)). 

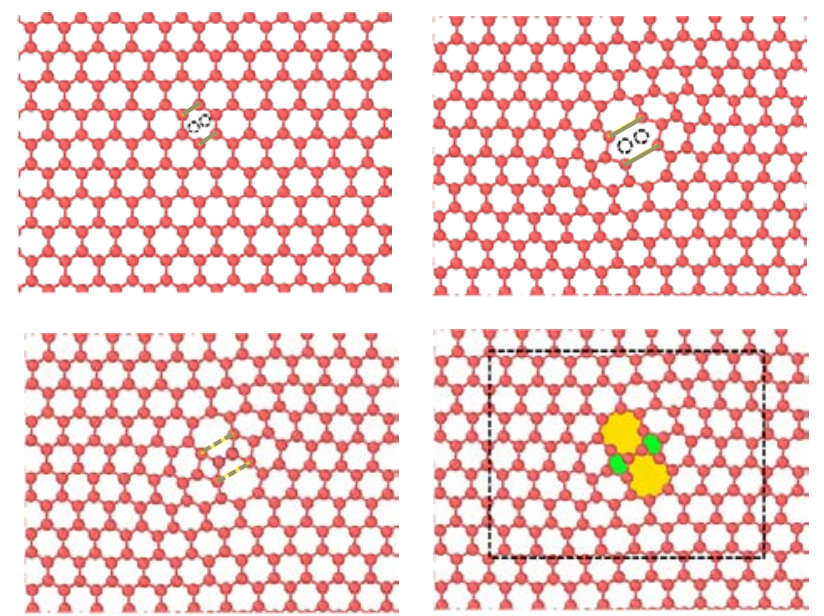

(a)

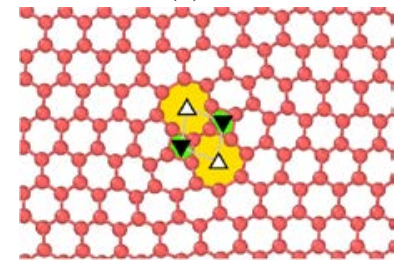

(b)

Fig. 9. (Color online) Quadrupole of wedge disclinations of strength $\omega=+2 \pi / 3$ and $-2 \pi / 3$ in graphene. (a) The sequential process of quadrupole formation by inserting two carbon atoms into a graphene lattice. (b) Disclination scheme of the quadrupole.

In Fig. 10 the periodic structures of small disclination quadrupoles containing 4- and 8-member rings, named "4-8" quadrupoles, are shown. As can be seen from Fig. 10(a), tightly packed quadrupoles take the form of the quadrats. Quadrat quadrupoles "4-8" of large size are also observed in the DNs shown in the Figs. 6(b)-(e). Here they are also tightly packed, i.e. the size of the quadrupole is DN half-period.

With increasing period of the quadrupole network (QN) their transformation is observed: they evolve from square (Fig. 10(a)) to parallelogram (Figs. 10(b)-(e). This is explained by considering the $\mathrm{QN}$ as composed of linear chains of quadrupoles "4-8” and 6-member carbon rings. It has been shown in the Ref. 34 that the intercrystallite boundary composed of only quadrupoles 4-8 does not introduce a misorientation of the neighboring crystals. Adding 6-member rings between the quadrupoles in the intercrystallite boundary "4-8" leads to the appearance of the misorientation angle in interval $0^{\circ}-60^{\circ}$. This is similar to the phenomenon found in the study of the " $5-7$ " grain boundaries in graphene [40].

In Fig. 11, the diagram of the energy per atom for graphene with periodic QNs, given in Fig. 10, is shown. As expected, with an increase of the period of QN, the average energy per atom of the disclinated crystal decreases.

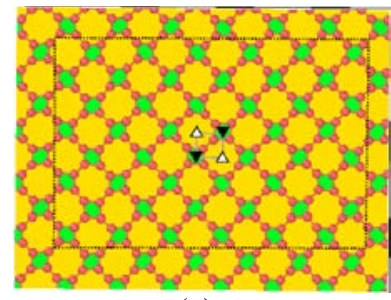

(a)

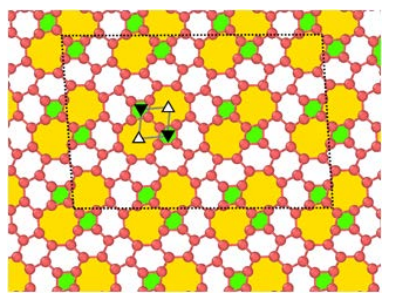

(b)

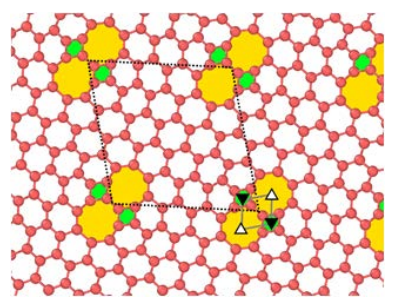

(c)

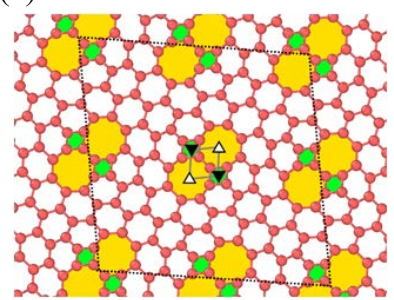

(d)

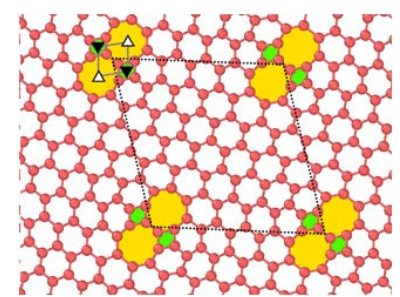

(e)
Fig. 10. (Color online) Networks of disclination qudrupoles in pseudo-graphene and graphene-like structures.

\section{Summary and Conclusions}

Resulting from our research, we formulate the following.

(i) The average energy of graphene with alternating disclination networks (DNs) remains practically unchanged with increasing DN period. The exceptions are the crystals with the densest DNs. These crystals contain a minimal number of 6-member carbon rings typical for ideal graphene, or do not have them at all. It is correct to call such 2D carbon crystals pseudo-graphenes. Pseudo-graphenes are low-energy

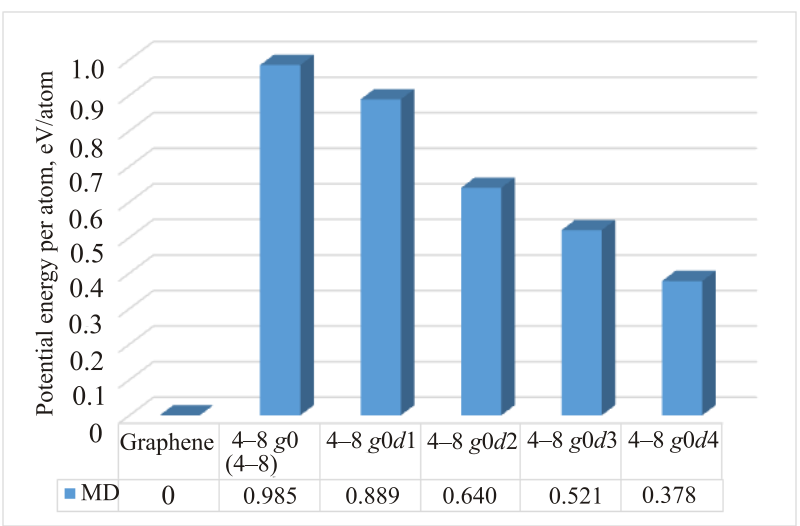

Fig. 11. Energy per atom for graphene-like 2D structures with periodic ensembles of disclination quadrupoles, given in Fig. 10. Crystal marked "4-8 $g 0$ ” is a pseudo-graphene "4-8". 
containing disclination defects configurations. The energies of pseudo-graphenes "5-7 A" and "5-7 B" exceed the energy of an ideal graphene by only $0.28-0.38 \mathrm{eV} /$ atom.

(ii) For an approximate estimate of the energy of graphene with embedded alternating DNs, one can use the analytical formulas for the energy of a single disclination quadrupole in the form suitable for a given DN.

\section{Acknowledgement}

The work was supported by the Russian Foundation for Basic Research (grant No 18-01-00884).

1. K.S. Novoselov, D. Jiang, F. Schedin, T.J. Booth, V.V. Khotkevich, S.V. Morozov, and A.K. Geim, Proc. Nat. Acad. Sci. U.S.A. 102, 10451 (2005).

2. M.I. Katsnelson, Graphene: Carbon in Two Dimensions, Cambridge University Press, New York (2012).

3. C.S. Ruiz-Vargas, H.L.L. Zhuang, P.Y. Huang, A.M. van der Zande, S. Garg, P.L. McEuen, D.A. Müller, R.G. Henning, and J. Park, Nano Lett. 11, 2259 (2011).

4. G.H. Lee, R.C. Cooper, S.J. An, S. Lee, A. van der Zande, N. Petrone, A.G. Hammerberg, C. Lee, B. Crawford, W. Oliver, J.W. Kysar, and J. Hone, Science 340, 1073 (2013).

5. H.I. Rasool, C. Ophus, W.S. Klug, A. Zettl, and J.K. Gimzewski, Nature Commun. 4, 2811 (2013).

6. K.L. Grosse, V.E. Dorgan, D. Estrada, J.D. Wood, I. Vlassiouk, G. Eres, J.W. Lyding, W.P. King, and E. Pop, Appl. Phys. Lett. 105, 143109 (2014).

7. L. Tapaszto, P. Nemes-Incze, G. Dobrik, Jae K. Yoo, C. Hwang, and L.P. Biro, Appl. Phys. Lett. 100, 053114 (2012).

8. Q. Yu, L.A. Jauregui, W. Wu, R. Colby, J. Tian, Z. Su, H. Cao, Z. Liu, D. Pandey, D. Wei, T.F. Chung, P. Peng, N.P. Guisinger, E.A. Stach, J. Bao, S.S. Pei, and Y.P. Chen, Nature Mater. 10, 443 (2011).

9. L.A. Jauregui, H. Cao, W. Wu, Q. Yu, and Y.P. Chen, Solid State Commun. 151, 1100 (2011).

10. D. Van Tuan, J. Kotakoski, T. Louvet, F. Ortmann, J.C. Meyer, and S. Roche, Nano Lett. 13, 1730 (2013).

11. K. Kim, Z. Lee, W. Regan, C. Kisielowski, M. F. Crommie, and A. Zettl, ACS Nano 5, 2142 (2011).

12. L.P. Biro, and Ph. Lambin, New J. Phys. 15, 035024 (2013).

13. K.S. Kim, Y. Zhao, H. Jang, S.Y. Lee, J.M. Kim, K.S. Kim, J.-H. Ahn, Ph. Kim, J.-Y. Choi, and B.H. Hong, Nature 457, 706 (2009).

14. P. Nemes-Incze, P. Vancso, Z. Osvath, G.I. Mark, X. Jin, Y.-S. Kim, Ch. Hwang, Ph. Lambin, Cl. Chapelier, and L.P. Biro, Carbon 64, 178 (2013).

15. J. An, E. Voelkl, J.W. Suk, X. Li, C.W. Magnuson, L. Fu, P. Tiemeijer, M. Bischoff, B. Freitag, E. Popova, and R.S. Ruoff, ACS Nano 5, 2433 (2011).

16. L. Gao, J.R. Guest, and N.P. Guisinger, Nano Lett. 10, 3512 (2010).

17. Y. Zhang, T. Gao, Y. Gao, S. Xie, Q. Ji, K. Yan, H. Peng, and Z. Liu, ACS Nano 5, 4014 (2011).
18. J. Lahiri, Y. Lin, P. Bozkurt, I.I. Oleynik, and M. Batzill, Nature Nanotechn. 5, 326 (2010).

19. P. Kim, Nature Mater. 9, 792 (2010).

20. O.V. Yazyev and S.G. Louie, Phys. Rev. B 81, 195420 (2010).

21. Y. Wei, J. Wu, H. Yin, X. Shi, R. Yang, and M. Dresselhaus, Nature Mater. 11, 759 (2012).

22. R. Grantab, V.B. Shenoy, and R.S. Ruoff, Science 330, 946 (2010).

23. S. Malola, H. Häkkinen, and P. Koskinen, Structural. Phys. Rev. B 81, 165447 (2010).

24. A. Mesaros, S. Papanikolaou, C. Flipse, D. Sadri, and J. Zaanen, Phys. Rev. B 82, 205119 (2010).

25. Y. Liu and B.I. Yakobson, Nano Lett. 102178 (2011).

26. T.-H. Liu, G. Gajewski, C.-W. Pao, and C.-C. Chang, Carbon 49, 2306 (2011).

27. J. Zhang and J. Zhao, Carbon 55, 151 (2013).

28. J. Kotakoski and J. Meyer, Phys. Rev. B 85, 195447 (2012).

29. M. Akhukov, A. Fasolino, Y. Gornostyrev, and M. Katsnelson, Phys. Rev. B 85, 115407 (2012).

30. A.Y. Serov, Z.-Y. Ong, and E. Pop, Appl. Phys. Lett. 102, 033104 (2013).

31. P. Yasaei, A. Fathizadeh, R. Hantehzadeh, A. K. Majee, A. El-Ghandour, D. Estrada, C. Foster, Z. Aksamija, F. KhaliliAraghi, and A. Salehi-Khojin, Nano Lett. 15, 4532 (2015).

32. Woosun Jang, Kisung Kang, Aloysius Soon, Nanoscale 7, 19073 (2015).

33. M.A. Rozhkov, A.L. Kolesnikova, T.S. Orlova, L.V. Zhigilei, and A.E. Romanov, Mater. Phys. Mech. 29, 101 (2016).

34. A.L. Kolesnikova, M.A. Rozhkov, I. Hussainova, T.S. Orlova, I.S. Yasnikov, L.V. Zhigilei, and A.E. Romanov, Rev. Adv. Mater. Science 52, 91 (2017).

35. Ch.-P. Tang and Sh.-J. Xiong, AIP Adv. 2, 042147 (2012).

36. A.S. Kochnev, I.A. Ovid'ko, and B.N. Semenov, Mater. Phys. Mech. 21, 275 (2014).

37. Zh. Wang, X.-F. Zhou, X. Zhang, Q. Zhu, H. Dong, M. Zhao, and A.R. Oganov, Nano Lett. 15, 6182 (2015).

38. V.D. Natsik and S.N. Smirnov, Fiz. Nizk. Temp. 40, 1366 (2014) [Low Temp. Phys. 40, 1063 (2014)].

39. A.L. Kolesnikova, T.S. Orlova, I. Hussainova, and A.E. Romanov, Phys. Solid State 56, 2573 (2014).

40. A.E. Romanov, A.L. Kolesnikova, T.S. Orlova, I. Hussainova, V.E. Bougrov, and R.Z. Valiev, Carbon 81, 223 (2015).

41. V.D. Natsik and S.N. Smirnov, Fiz. Nizk. Temp. 41, 271 (2015) [Low Temp. Phys. 41, 207 (2015)].

42. V.D. Natsik and S.N. Smirnov, Fiz. Nizk. Temp. 42, 268 (2016) [Low Temp. Phys. 42, 207 (2016)].

43. A.L. Kolesnikova, M.Yu. Gutkin, and A.E. Romanov, Rev. Adv. Mater. Science 51, 130 (2017).

44. A.E. Romanov and V.I. Vladimirov, Disclinations in Crystallinear Solids, in: Dislocations in Solids, F.R.N. Nabarro (ed.), North-Holland, Amsterdam (1992).

45. A.E. Romanov and A.L. Kolesnikova, Progr. Mater. Science 54, 740 (2009).

46. W.F. Harris, Scientific Amer. 237, 130 (1977).

47. A.L. Kolesnikova and A.E. Romanov, Phys. Solid State 40, 1075 (1998). 
48. V.G. Gryaznov, J. Heydenreich, A.M. Kaprelov, S.A. Nepijko, A.E. Romanov, and J. Urban, Cryst. Res. Techn. 34, 1091 (1999).

49. A.E. Romanov, A.L. Kolesnikova, I.S. Yasnikov, A.A. Vikarchuk, M.V. Dorogov, A.N. Priezzheva, L.M. Dorogin, and E.C. Aifantis, Rev. Adv. Mater. Science 48, 170 (2017).

50. http://lammps.sandia.gov.

51. S.J. Stuart, A.B. Tutein, and J.A. Harrison, J. Chem. Phys. 112, 6472 (2000).

52. http://www.ovito.org/.

53. E. Polak and G. Ribiere, Revue Française d'Informatique et de Recherche Opérationnelle, Série Rouge 3, 35 (1969).

54. I.S. Yasnikov, A.L. Kolesnikova, and A.E. Romanov, Phys. Solid State 58, 1184 (2016).

\section{Ансамблі дисклінацій у графені \\ М.А. Рожков, А.Л. Колеснікова, І.С. Ясніков, А.Е. Романов}

Розглянуто дисклінаційні сітки (DNs) - періодичні розподіли дисклінаційних дефектів у графені. Дисклінації проявляють себе як 4-, 5-, 7- або 8-членні вуглецеві кільця на відміну від 6-ланкових кілець, з яких складається двовимірна 2D ідеальна гратка графена. Також досліджено граничні випадки графеноподібних 2D вуглецевих граток без 6-ланкових кілець - так звані псевдографени. Геометрія та енергія дисклінованих 2D-вуглецевих конфігурацій аналізуються за допомогою метода молекулярної динаміки (MD). Наведено порівняння результатів MD моделювання та аналітичних розрахунків в рамках теорії дефектів пружного континууму.

Ключові слова: графен, псевдографен, дисклінація, дискліноване вуглецеве кільце, дисклінаційний квадруполь, сітка дисклінацій, молекулярна динаміка.

\section{Ансамбли дисклинаций в графене \\ М.А. Рожков, А.Л. Колесникова, И.С. Ясников, А.Е. Романов}

Рассмотрены дисклинационные сетки (DNs) - периодические распределения дисклинационных дефектов в графене. Дисклинации проявляют себя как 4-, 5-, 7- или 8-членные углеродные кольца в отличие от 6-звенных колец, из которых состоит двумерная (2D) идеальная решетка графена. Также исследуются предельные случаи графеноподобных 2D углеродных решеток без 6-звенных колец - так называемые псевдографены. Геометрия и энергия дисклинированных 2D углеродных конфигураций анализируются с помощью метода молекулярной динамики (MD). Представлено сравнение результатов MD моделирования и аналитических расчетов, проведенных в рамках теории дефектов упругого континуума.

Ключевые слова: графен, псевдографен, дисклинация, дисклинированное углеродное кольцо, дисклинационный квадруполь, сетка дисклинаций, молекулярная динамика. 